\title{
ERS task force statement: diagnosis and treatment of primary spontaneous pneumothorax
}

\author{
Jean-Marie Tschopp ${ }^{1,13}$, Oliver Bintcliffe ${ }^{2}$, Philippe Astoul ${ }^{3}$, Emilio Canalis ${ }^{4}$, \\ Peter Driesen ${ }^{5}$, Julius Janssen ${ }^{6}$, Marc Krasnik$^{7}$, Nicholas Maskell ${ }^{2}$, \\ Paul Van Schil ${ }^{8}$, Thomy Tonia9, David A. Waller ${ }^{10}$, Charles-Hugo Marquette ${ }^{11}$ \\ and Giuseppe Cardillo ${ }^{12,13}$
}

\begin{abstract}
Affiliations: ${ }^{1}$ Centre Valaisan de Pneumologie, Dept of Internal Medicine RSV, Montana, Switzerland ${ }^{2}$ Academic Respiratory Unit, School of Clinical Sciences, University of Bristol, Bristol, UK. ${ }^{3}$ Dept of Thoracic Oncology, Pleural Diseases and Interventional Pulmonology, Hospital North Aix-Marseille University, Marseille, France. ${ }^{4}$ Dept of Surgery, University of Rovira I Virgili, Tarragona, Spain. ${ }^{5}$ Dept of Pneumology, AZ Turnhout, Turnhout, Belgium. 'Dept of Pulmonary Diseases, Canisius Wilhelmina Hospital, Nijmegen, The Netherlands. ${ }^{7}$ Dept of Cardiothoracic Surgery, Rigshospitalet, Copenhagen, Denmark. ${ }^{8}$ Dept of Thoracic and Vascular Surgery, Antwerp University Hospital, Antwerp, Belgium. ${ }^{9}$ Institute of Social and Preventative Medicine, University of Bern, Bern, Switzerland. ${ }^{10}$ Dept of Thoracic Surgery, Glenfield Hospital, Leicester, UK. ${ }^{11}$ Hospital Pasteur CHU Nice and Institute for Research on Cancer and Ageing, University of Nice Sophia Antipolis, Nice, France. ${ }^{12}$ Dept of Thoracic Surgery, Carlo Forlanini Hospital, Azienda Ospedaliera San Camillo Forlanini, Rome, Italy. ${ }^{13}$ Task Force Chairs.
\end{abstract}

Correspondence: Jean-Marie Tschopp, Centre Valaisan de Pneumologie, 3963 Montana, Switzerland.

E-mail: jean-marie.tschopplanetplus.ch

ABSTRACT Primary spontaneous pneumothorax (PSP) affects young healthy people with a significant recurrence rate. Recent advances in treatment have been variably implemented in clinical practice. This statement reviews the latest developments and concepts to improve clinical management and stimulate further research.

The European Respiratory Society's Scientific Committee established a multidisciplinary team of pulmonologists and surgeons to produce a comprehensive review of available scientific evidence.

Smoking remains the main risk factor of PSP. Routine smoking cessation is advised. More prospective data are required to better define the PSP population and incidence of recurrence. In first episodes of PSP, treatment approach is driven by symptoms rather than PSP size. The role of bullae rupture as the cause of air leakage remains unclear, implying that any treatment of PSP recurrence includes pleurodesis. Talc poudrage pleurodesis by thoracoscopy is safe, provided calibrated talc is available. Video-assisted thoracic surgery is preferred to thoracotomy as a surgical approach.

In first episodes of PSP, aspiration is required only in symptomatic patients. After a persistent or recurrent PSP, definitive treatment including pleurodesis is undertaken. Future randomised controlled trials comparing different strategies are required.

@ERSpublications

A European Task Force reviews scientific evidence and suggests future research for primary spontaneous pneumothorax http://ow.ly/MWhuF 


\section{Introduction}

Spontaneous pneumothorax was first described in 1819 by LAËNNEC [1] and has been traditionally categorised as primary or secondary spontaneous pneumothorax (PSP and SSP, respectively). PSP is defined as a spontaneous pneumothorax occurring in patients without a prior known underlying lung disease [2]. It remains the subject of ongoing debate, despite important progress achieved in both medical and surgical treatments.

PSP is associated with low rates of morbidity and mortality, typically affects a young population and has a recurrence rate of between $17 \%$ and $54 \%$ [3-7]. Aetiological mechanisms of PSP are better appreciated following contemporary pathophysiological studies $[8,9]$. The last few decades have seen advances in both the diagnosis and the treatment of spontaneous pneumothorax. Some newer approaches, however, remain poorly implemented in standard clinical practice [4, 6, 10-17]. The European Respiratory Society (ERS) is updating this statement regarding PSP in order to present the latest developments and concepts, with the aim of improving clinical management and stimulating further high quality research in this important area.

\section{Methods}

During the 2012 ERS Annual Congress in Vienna (Austria), a European Task Force was formed of 12 clinical and scientific experts, comprising seven pulmonologists and five surgeons from eight European countries. The Task Force was established according to the recommendations of the ERS Scientific Committee for development of a statement that is a comprehensive scientific review by a group of experts (table 1). The statement is based on a body of scientific evidence identified by systematic searches and documented by references supporting the conclusions [18]. Initially, a set of key clinical questions in five sections was formulated on epidemiology, diagnosis, classification, treatment of first episode and treatment of recurrent or complicated PSP. To obtain a body of scientific evidence, a systematic literature search was performed on medical databases (Medline/PUBMED (National Library of Medicine, USA), EMBASE (Elsevier, the Netherlands), Cochrane Library (UK)) by the librarian of the University of Geneva Faculty of Medicine (Geneva, Switzerland) under the supervision of a Task Force member (J-M. Tschopp). The initial search was performed in February 2013 and repeated in September 2014. The search was limited to reference material regarding adult patients published since 1993. Well-balanced subgroups of two to four members, including both pulmonologists and thoracic surgeons, prepared first drafts for each section. In the first plenary session, all sections were read and discussed and a consensus was established. A subsequent writing committee (J-M. Tschopp, G. Cardillo, N. Maskell and O. Bintcliffe) prepared a second draft that was sent to all Task Force members, who provided written feedback. A third draft was prepared by the writing committee and revised again by all Task Force members. A final draft was discussed and approved in a final plenary session during the 2014 ERS International Congress in Munich (Germany). The final document therefore represents the consensus of the Task Force members. This statement describes the current evidence and practices for PSP. It does not make recommendations for clinical practice. This statement has been endorsed by the ERS Scientific Committee.

TABLE 1 Methodology checklist

Panel assembly

Experts from chest medicine and thoracic surgery

Experts vetted for conflict of interest

Patient representative

Expert methodologist

Literature review

Performed in collaboration with librarian

Searched in multiple electronic databases (Medline/PUBMED, EMBASE, Cochrane Library)

Reviewed reference list of retrieved articles

\section{Evidence synthesis}

Prespecified inclusion and exclusion criteria applied

Evaluation of included studies for source of bias

Explicitly summarised benefits and harms

Grading system used 


\section{Epidemiology of primary spontaneous pneumothorax}

The incidence of PSP in a population around Stockholm (Sweden) between 1975 and 1984 was 18 per 100000 per year in males and six per 100000 per year in females [19]. Between 1991 and 1995, combined annual rates of primary and secondary pneumothorax in England were 24 per 100000 for men and 9.8 per 100000 for women in a study analysing three national databases [20]. Annual costs in the USA have been estimated at $\$ 130$ million [21].

The most important risk factor for PSP is tobacco smoking. The retrospective study in Stockholm assessed the smoking rates of 138 patients admitted to hospital over a 10-year period and compared their rates of smoking with a large contemporary random sample of people from the same area. Of the patients with PSP, $88 \%$ smoked. Compared with nonsmokers, the relative risk of a first spontaneous pneumothorax was increased nine-fold in women and 22-fold in men who smoked [19]. Additionally, a strong dose-response relationship was detected in this study between risk of pneumothorax and number of cigarettes smoked per day [19].

Cannabis smoking shares common pathological processes and an overlapping spectrum of lung disease with tobacco smoking; however, cannabis smoke has been demonstrated to be particularly associated with bullous disease. Multiple large peripheral bullae at the lung apex are often seen in young patients with a history of cannabis smoking, in the absence of significant parenchymal damage elsewhere. In addition, the duration of exposure is shorter than would be expected in the development of these abnormalities due to tobacco smoke alone [22]. Differences in the physical mechanism of inhalation when smoking cannabis are described as being a potential explanation for the development of this accelerated pattern of lung damage that predisposes to pneumothorax [23-25].

Cases of PSP have been shown to exhibit clustering, an effect that has been hypothesised to be due to changes in atmospheric pressure [26] or levels of air pollution [27]. Height has been demonstrated to be a risk factor for PSP [28] and recent studies have shown a high prevalence of low body mass index (BMI) in patients with PSP [29].

Catamenial pneumothorax is a rare condition that affects women of reproductive age, in a temporal relationship with menses. These recurrent episodes of pneumothorax occur within $72 \mathrm{~h}$ before or after the start of menstruation. Catamenial pneumothorax is thought to be underdiagnosed, with a recent large retrospective study showing it to be the underlying cause in over $30 \%$ of pre-menopausal women who were surgically treated for spontaneous pneumothorax [30]. Although catamenial pneumothorax is often associated with the presence of thoracic endometriosis, most commonly the only abnormalities seen at the time of surgery are diaphragmatic defects [31]. They can be single or multiple, are usually located at the central tendon, and range in size from tiny holes $(1-3 \mathrm{~mm})$ to larger defects $(>10 \mathrm{~mm})$ [31]. Therefore, at the time of surgery, the diaphragm, parietal pleura, lung and pericardium are inspected meticulously, any diaphragmatic holes are repaired and any thoracic lesions resected and sent for histological analysis [32]. Despite these measures, the recurrence rate is high (32\% in one series [33]), leading some authors to suggest the administration of a gonadotrophin-releasing hormone analogue (leading to amenorrhoea) for 6-12 months after surgery [31, 34].

The onset of PSP typically occurs at rest (80\%) and is characteristically associated with chest pain (81\%) and dyspnoea (39\%) [35]. The incidence of recurrence of PSP is reported to range between $17 \%$ and $54 \%$ in the first year following pneumothorax $[4,7]$. Pneumothorax as a whole has a bimodal age distribution: PSP peaks between the ages of 15 and 34 years and SSP in those aged $>55$ years [20].

In summary, smoking tobacco remains the main risk factor for PSP. Marijuana smoking also increases the risk of pneumothorax [36]. More prospective data are required to better define the population at risk and the true incidence of recurrence.

\section{Clinical evaluation of primary spontaneous pneumothorax Symptoms}

Typically, patients present with an abrupt onset of pleuritic chest pain with or without breathlessness and some patients may experience shoulder tip pain [37]. Commonly, symptoms are minimal or even totally absent, in contrast to the presentation of secondary pneumothorax, in which breathlessness is a predominant feature. Symptoms usually improve following presentation of PSP; a worsening of symptoms is very rare and when it occurs, it suggests the development of complications (such as haemopneumothorax) or an alternative aetiology.

\section{Clinical examination}

Typical examination findings in PSP include reduced or absent breath sounds, reduced ipsilateral chest expansion and hyper-resonant percussion [38]. Haemodynamic compromise or significant hypoxia is 
unusual in primary pneumothorax [39]. In view of the variability of symptoms and signs at presentation, the diagnosis of primary pneumothorax is usually confirmed with radiographic imaging.

\section{Chest radiograph}

Posterior-anterior chest radiographs remain the standard examination in patients with suspected PSP and may be combined with lateral radiographs in difficult cases [40]. The radiographic hallmark is displacement of the pleural line and an absence of lung markings between the edge of the pleura and chest wall. The value of routine expiratory films in the diagnosis of pneumothorax has been evaluated in studies with paired inspiratory and expiratory chest radiographs and has demonstrated that pneumothoraces can be reliably diagnosed with inspiratory radiographs alone $[41,42]$.

\section{Computed tomography}

Computed tomography (CT) is more sensitive than chest radiographs in the detection of pneumothorax [43-46]. However, it is not required in the majority of cases, as the diagnosis may be clearly made on a chest radiograph and an excess radiation dose should be avoided in this young patient population [47]. It may be possible to adjust the imaging protocol to minimise radiation dose depending on the indications for imaging. Cross-sectional imaging may be useful in complicated cases, in suspected tube misalignment, where underlying lung disease is suspected [48] and in patients requiring surgery.

\section{Ultrasound}

In the past decade, lung ultrasonography has emerged as a sensitive technique in the evaluation of respiratory diseases, and it has gained a well-established role in the diagnosis of pneumothorax in trauma and critically ill patients [45, 49-54]. Recent studies have evaluated ultrasound in trauma patients, in whom it has shown a sensitivity of $98 \%$, a negative predictive value of $82 \%$ and a positive predictive value of $100 \%$ [55]. These studies showed significantly higher diagnostic yield with ultrasound than chest radiographs, with CT used as the reference examination [56-58]. The routine use of ultrasound in PSP, however, has not yet been well established.

\section{Classification and pathophysiology of pneumothorax}

The distinction between primary, secondary, traumatic and iatrogenic pneumothorax is important in view of the different management strategies required for their treatment.

A spontaneous pneumothorax occurs in the absence of any identified extrinsic cause. PSP occurs in the absence of clinically apparent underlying lung disease, while SSP occurs as a complication of a pre-existing underlying lung disease such as chronic obstructive pulmonary disease [59, 60], cystic fibrosis [61-63], lung malignancy (primary or metastatic) or necrotising pneumonia of various causes [64-67].

The distinction between PSP and SSP is becoming increasingly blurred, as patients with PSP may be found to have subtle undiagnosed pulmonary abnormalities on further investigation $[68,69]$. This may lead to an alternative classification system in the future.

Recurrent pneumothorax is defined as a subsequent episode of pneumothorax occurring after either an ipsilateral or contralateral pneumothorax.

Tension pneumothorax occurs when the intrapleural pressure becomes greater than the atmospheric pressure throughout all phases of respiration. It can be seen in ventilated patients or after trauma or cardiopulmonary resuscitation, but is extremely rare in PSP [70].

Size of the pneumothorax

The estimation of the size is traditionally based on the Light index [71]:

$$
\text { Size of } \operatorname{PSP}(\%)=\left(1-\left(\frac{\text { Average lung diameter }}{3}\right)\right) \times 100
$$

A study used this method and found a strong correlation between the estimated size and the volume of air removed from the pleural space during drainage [18]. However, a comparison between the estimated size of a pneumothorax using the Light index and CT volumetrics, derived by the Collins method, found poor agreement between the methods [72]. The average difference was 7.3\%, with the Light index underestimating the size relative to the Collins method. The $95 \%$ limits of agreement were wide $(24 \%$ underestimation to $17 \%$ overestimation of size), demonstrating that the Light index does not accurately estimate the size of pneumothorax [73]. 
Although CT scanning is the best method of measuring the size of the pneumothorax, a precise estimate of size has little clinical value. There is considerable variability in previous international guidelines on the treatment for pneumothorax. There is general agreement that treatment is required for clinically compromised patients. For clinically stable patients, treatment recommendations have been based, at least in part, on the size of pneumothorax (small or large), although the definition of a large pneumothorax differs $[6,21]$. A study comparing the size classifications used by the different guidelines demonstrated poor agreement between them [72], and there is no contemporary evidence to support the approach of treatment decisions based on size of pneumothorax alone. Most Task Force members adopt a symptom-driven approach, with follow-up to ensure resolution, rather than basing initial management on size alone.

\section{Pathophysiology}

The precise pathogenesis of PSP is not completely understood. With the improvement of imaging techniques, blebs and bullae can be visualised ipsilaterally or bilaterally in almost all patients with PSP during surgery, medical thoracoscopy or CT scan [74-77]. These changes visible on the visceral pleura have been called emphysema-like changes (ELCs), which are also recognised as a specific entity. Recently, in a subset of patients with spontaneous pneumothorax, fibroblastic lesions consisting of pleural fibrosis with islands of fibroblastic foci within a myxoid stroma have been described [78]. It is generally believed that pneumothorax results from the rupture of ELCs, based on a hypothesis of VANDERSCHUEREN [79], who thought that there was a continuous evolution from normal pleura to blebs and then progressive larger bullae rupturing leading to occurrence of PSP; however, this has never been proved. Sites of lung rupture are difficult to demonstrate during surgery or on resected pieces of lung [80-82]. Two studies compared the appearance of blebs and bullae in first episode and recurrence of PSP and did not find any significant differences in size, number or location of blebs and bullae, either by medical thoracoscopy or CT scan [83, 84], raising doubts about the aforementioned assumption [79] and the role of blebs and bullae rupture as the main factor explaining the occurrence of PSP. More recently, CASALI et al. [85], using high-resolution CT scans, developed a new severity score for abnormalities of the visceral pleura in PSP and demonstrated a significant correlation between the severity of this score and the risk of recurrence of PSP at follow-up. These results, obtained in a retrospective series, require confirmation in prospective studies but do suggest a population at risk who may benefit from more invasive treatment.

Thorough examination of resected specimens of lung in cases of PSP does not demonstrate macro- and microscopic sites of air leakage [86] but diffuse areas of disrupted mesothelial cells in the visceral pleura, replaced by a layer of inflammatory cells with increased "elastofibrosis process" and pores of 10-20 mm in diameter, suggesting the presence of diffuse pleural porosity [80, 86, 87]. The development of a new technique of fluorescein-enhanced autofluorescence thoracoscopy [88] clearly showed many areas of fluorescein leakage on the visceral pleura even in normal areas, as seen by normal light, lending weight to the idea of diffuse pleural porosity. These diffuse histological changes on the visceral pleura may explain the high recurrence rate (20\%) following bullectomy alone without an associated pleurodesis [82, 89-91].

This also leads to an important practical question: what is the respective weight of blebs, bullae and ELCs in the aetiology of air leakage (fig. 1). There is evidence that the presence of ELCs and pleural porosity is related to other factors, such as patient height, distal airway inflammation, hereditary predisposition, low BMI and abnormal connective tissue, which may predispose to PSP [70].

In summary, the true role of rupture of blebs and bullae as a cause of air leakage in spontaneous pneumothorax is not clear [92].

FIGURE 1 A piece of resected lung parenchyma in a case of recurring primary spontaneous pneumothorax. Image courtesy of A. Spiliopoulos (Faculty of Medicine, University of Geneva, Geneva, Switzerland).

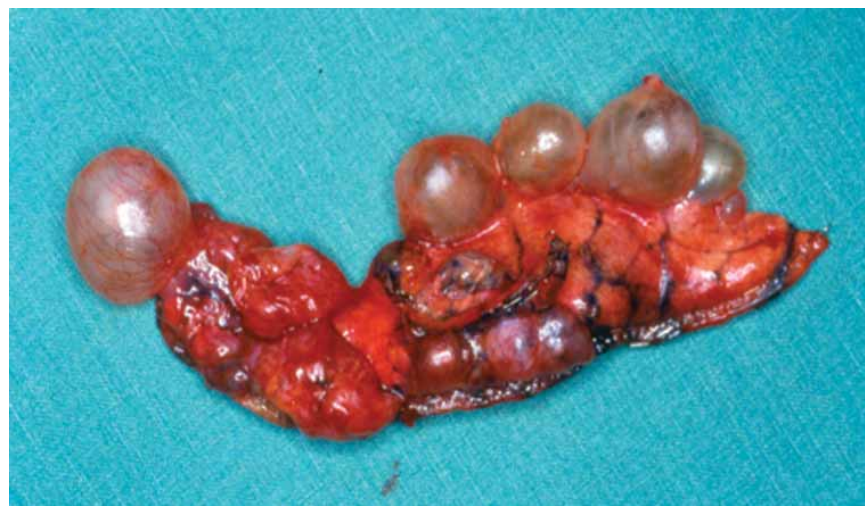


Treatment of first episodes of primary spontaneous pneumothorax

Overall, treatment of PSP has two goals: evacuation of air, if necessary, and the prevention of recurrence.

What is the role of conservative management?

In recent years there has been a move towards a more conservative approach to management, based on the principle that intrapleural air does not necessarily require a therapeutic intervention, and that management depends on the clinical symptoms and not on the size of the pneumothorax $[6,93]$. This conservative approach may be appropriate as tension pneumothorax from a PSP is extremely rare [10, 70]. In selected patients with minimal or no symptoms and good access to medical care in case of deterioration, observation alone may be appropriate.

Within the current British Thoracic Society (BTS) guidelines (from 2010), there is a significant emphasis on a conservative approach to treatment [6] with management predominantly based on clinical symptoms. In contrast, the American College of Chest Physicians (ACCP) Delphi consensus statement (from 2001) recommended a more aggressive approach, with intercostal drain placement recommended in any pneumothorax larger than $20 \%$ of the hemithorax, irrespective of the symptoms [21].

\section{Percutaneous needle aspiration or thoracic drain?}

Removal of air from the pleural space can be achieved with needle aspiration or chest drain insertion. BTS and ACCP guidelines differ in their view of the utility of needle aspiration, with BTS guidelines suggesting aspiration as an initial intervention in patients with a large or symptomatic primary pneumothorax and ACCP guidelines not suggesting this approach for any patients. Randomised trials published from 1994 onwards are summarised in table 2, with data on the success of aspiration and chest drain insertion.

From this table, the evidence suggests that needle aspiration is effective for the initial management of spontaneous pneumothorax. Following aspiration, patients may be discharged, avoiding hospital admission, although insertion of a small-bore chest tube attached to a Heimlich valve may yield similar results $[99,100]$. It should be noted that failure with aspiration occurs at a frequency of $25-50 \%$ in PSP $[9,101]$ and that after a failed aspiration there is no evidence to support a second aspiration over chest drain insertion.

Small- or large-bore chest tubes?

In a retrospective Danish study, smaller bore (11-13 French) tubes seemed to perform better than larger drains (20-28 French) with regard to short-term outcomes [102]. This finding was also noted in two non-randomised studies in young adolescents, in whom small-bore pigtail catheters were found to be as effective as large-bore catheters $[103,104]$. Two prospective French studies have shown that ambulatory

\begin{tabular}{|c|c|c|c|c|c|c|}
\hline First author [ref.] & Year & Patients n & Outcome & Aspiration & Chest drain & Difference \\
\hline HARVEY [94] & 1994 & 73 & $\begin{array}{l}\text { Success } \\
\text { Hospital stay days } \\
\text { Recurrence at } 1 \text { year }\end{array}$ & $\begin{array}{l}80 \\
3.2 \\
17\end{array}$ & $\begin{array}{l}100 \\
5.3 \\
29\end{array}$ & $\begin{array}{c}\text { ND } \\
p=0.005 \\
\text { NS }\end{array}$ \\
\hline ANDRIVEt [95] & 1995 & 61 & $\begin{array}{l}\text { Success } \\
\text { Hospital stay days } \\
\text { Recurrence at } 3 \text { months }\end{array}$ & $\begin{array}{c}67 \\
7 \\
14\end{array}$ & $\begin{array}{c}93 \\
7 \\
29\end{array}$ & $\begin{array}{l}p=0.01 \\
\text { NS } \\
\text { NS }\end{array}$ \\
\hline NopPen [96] & 2002 & 60 & $\begin{array}{l}\text { Immediate success } \\
\text { Admissions } \\
\text { Success at } 1 \text { week } \\
\text { Recurrence at } 1 \text { year }\end{array}$ & $\begin{array}{l}59 \\
52 \\
93 \\
26\end{array}$ & $\begin{array}{c}64 \\
100 \\
85 \\
27\end{array}$ & $\begin{array}{c}\text { NS } \\
p<0.0001 \\
\text { NS } \\
\text { NS }\end{array}$ \\
\hline AyEd [97] & 2006 & 137 & $\begin{array}{l}\text { Immediate success } \\
\text { Success at } 1 \text { week } \\
\text { Recurrence at } 1 \text { year }\end{array}$ & $\begin{array}{l}62 \\
89 \\
22\end{array}$ & $\begin{array}{l}68 \\
88 \\
24\end{array}$ & $\begin{array}{l}\text { NS } \\
\text { NS } \\
\text { NS }\end{array}$ \\
\hline PARLAK $^{\#}$ [98] & 2012 & 56 & $\begin{array}{l}\text { Immediate success } \\
\text { Success at } 2 \text { weeks } \\
\text { Recurrence at } 1 \text { year }\end{array}$ & $\begin{array}{c}68 \\
100 \\
4\end{array}$ & $\begin{array}{c}81 \\
100 \\
13\end{array}$ & $\begin{array}{l}\text { NS } \\
\text { NS } \\
\text { NS }\end{array}$ \\
\hline
\end{tabular}

Data are presented as percentages, unless otherwise stated. ND: not done; NS: nonsignificant. * : includes traumatic pneumothorax. 
management of a first episode of PSP with a small-bore drain and a one-way valve is a reasonable alternative to manual aspiration or chest tube drainage and results in significant reductions in overall hospital costs [7, 104]. Additionally, a retrospective study of 55 patients treated with small-bore chest drains connected to Heimlich valves found them to be an effective treatment of PSP [105].

\section{Suction or no suction?}

There are few data regarding the utility of applying suction to chest tubes in PSP. Lung re-expansion is achieved in up to $70 \%$ of patients with chest tube drainage alone by day 3 without suction [7, 104]. Expert opinion suggests there is no role for the immediate use of suction in all cases [6]; however, a small proportion of patients may benefit from the application of suction in the case of ongoing air leak, where apposition of lung may be achieved through its use. Prolonged use of suction may result in a delay to definitive management, which is associated with poorer clinical outcomes [106]. The use of a digital suction device, capable of quantifying air leak, has been demonstrated to reduce duration of drainage as well as the duration and cost of hospitalisation in patients with an air leak after spontaneous pneumothorax [107].

\section{Recurrence prevention and indications for definitive treatment}

In the first episode of PSP, the precise role of invasive treatment to evacuate air and prevent recurrence of spontaneous pneumothorax is a hotly debated topic and no randomised evidence is available [108, 109]. Recently, CHen et al. [4] randomised 214 patients with a first episode of PSP (size $>2 \mathrm{~cm}$ ) to pigtail catheter drainage alone or to catheter drainage followed by pleurodesis with $300 \mathrm{mg}$ of minocycline. There were no specific complications related to either procedure. After a 1-year follow-up period, recurrent pneumothorax occurred in $49.1 \%$ of patients in the control group compared with $29.2 \%$ in the minocycline group $(\mathrm{p}=0.003)$. The authors concluded that minocycline pleurodesis is safe and effective and should become the preferred treatment for PSP [4]. However, the 49\% 1-year recurrence rate in the control arm is considerably greater than that seen in previous literature in this area and minocycline is not universally available. This study alone is therefore not adequate to change practice until the results are replicated in further studies [13].

In summary, the decision to evacuate air from pleural space is usually determined primarily by the patients' symptoms or wishes, secondarily by their ability to carry out their normal daily activities, and lastly by the size of the pneumothorax. The potential risks of pleural intervention are taken into consideration in making management decisions.

\section{Air travel}

Recommendations for air travel passengers after pneumothorax are largely based on anecdotal case reports $[110,111]$. A pneumothorax, especially an undrained pneumothorax, is however an absolute contraindication to commercial air travel [112]. Definitive treatment reduces the risk of recurrence and makes air travel safer [110]; however, an individual clinical decision is usually made by the treating clinician, taking into account both airline policy and details of relevant insurance.

\section{Management of persistent or recurrent primary spontaneous pneumothorax}

The management of persistent or recurrent PSP continues to be debated [108, 113], partly because of the lack of well-conducted randomised controlled studies in this area. However, there is general agreement that an attempt at definitive treatment should be offered to patients with recurrent or persistent PSP and that this treatment should be cost-effective and based on the best scientific evidence $[6,21]$.

\section{Indications}

The indications for definitive treatment of PSP are summarised in table 3. In recurrent PSP, definitive treatment is offered as soon as practical. A chest tube may be avoided except in clinically unstable patients as a bridge to definitive treatment. In persistent PSP with ongoing air leak longer than 3-5 days, therapeutic options are discussed with the patient. The likelihood of resolution of the air leak and the risks and benefits of prolonged drainage or intervention are considered when making management decisions [106, 114].

TABLE 3 Indications for definitive management of primary spontaneous pneumothorax (PSP)

Second episode of PSP

Persisting air leak $>3-5$ days

Haemopneumothorax

Bilateral pneumothorax

Professions at risk (aircraft personnel, divers) 
Pleural procedures: pleurodesis

Pleurodesis aims to achieve pleural symphysis and prevent recurrence of pneumothorax. It can be performed by instilling a chemical irritant (chemical pleurodesis), by performing mechanical abrasion (mechanical pleurodesis) or with parietal pleurectomy (table 4). Currently, talc is the most commonly used agent in Europe.

Talc is administered as poudrage by thoracoscopy. In Europe the technique of talc poudrage is a very old, simple and cheap procedure performed under visual control by medical thoracoscopy and local anaesthesia $[116,124]$. It is also at present administered during video-assisted thoracic surgery (VATS) with an excellent and similar success rate $[118,125]$. Direct visualisation of poudrage allows a diffuse spreading of talc throughout the pleural cavity. The long-term success rate after simple thoracoscopic talc poudrage was $93-97 \%$ in a report of 13 published series including 505 patients in the 1980s [116].

Debate about the safety of talc originated from case reports, mainly from the USA and Brazil, which highlighted morbidity and mortality associated with the use of talc [126-130]. Research has since shown general dissemination of talc in animals with ungraded talc [131], which was not seen in a similar study using large particle talc [132]. NAVARRO JIMÉNEZ et al. [133] compared a variety of forms of talc originating from 13 countries and showed marked differences in the diameter of talc particles. MASKELL et al. [134] later showed in humans that systemic side-effects differed depending on whether large or small particle talc had been used. A recent Canadian study reported respiratory compromise in 14 out of 138 patients after talc poudrage using only American Food and Drug Administration approved talc [135], whereas two large European prospective cohorts demonstrated the safety of talc used in Europe in terms of incidence of acute respiratory distress syndrome $[17,136]$. The safety of talc has been further established with the observation that talc poudrage does not alter lung function [117, 118, 125, 137]. Following talc pleurodesis, VATS has been shown to be feasible [138, 139]; however, it is the opinion of some Task Force members that it is more technically demanding [106]. Talc poudrage is very cost-effective and, in fact, more economical than a conservative approach using only chest tube drainage [140]. A European multicentre randomised controlled study compared treatment of PSP with a chest tube alone with simple talc poudrage by medical thoracoscopy and found a higher recurrence rate in the chest tube group than in the talc poudrage group ( $27 \%$ versus $5 \%$, respectively), resulting in a reduced total healthcare cost in the poudrage group [115]. Talc poudrage under thoracoscopy is a safe, cheap and very efficient agent for achieving pleurodesis provided graded talc is chosen for pleurodesis [119, 120, 141, 142]. The recurrence rate seen after talc poudrage is comparable to that seen after mechanical pleurodesis [143-145]. Other sclerosing agents given via a chest tube have been used for prevention of pneumothorax, and include bleomycin dextrose, glucose 50\%, iodine, tetracycline or talc slurry [146]. Tetracycline has also been used but is less efficacious than talc poudrage $[116,147]$ and is no longer available in many countries [148]. Talc slurry is not used in patients with PSP as these patients are able to tolerate pleurodesis with poudrage, which is more effective $[9,149,150]$. The alternative agents are less well studied and sometimes potentially dangerous [151]. Following minocycline pleurodesis, in patients subsequently requiring surgical

TABLE 4 Recurrence rates after definitive treatment of primary spontaneous pneumothorax

\begin{tabular}{|c|c|c|c|c|}
\hline Study & Year & $\begin{array}{c}\text { Patients } \\
\text { n }\end{array}$ & $\begin{array}{l}\text { Mean follow-up } \\
\text { months }\end{array}$ & $\begin{array}{l}\text { Recurrence } \\
\quad \text { rate } \%\end{array}$ \\
\hline \multicolumn{5}{|c|}{$\begin{array}{l}\text { Simple talc poudrage under medical } \\
\text { thoracoscopy }\end{array}$} \\
\hline Tsснорт [115] & 2002 & 59 & 60 & 5 \\
\hline Boutin [116] & 1991 & 505 & 42 & 7 \\
\hline EL KHAWAND [117] & 1995 & 142 & 39 & 6 \\
\hline GYÖRIK [118] & 2007 & 56 & $118^{\#}$ & 5 \\
\hline \multicolumn{5}{|c|}{$\begin{array}{l}\text { Talc poudrage with VATS and surgical } \\
\text { treatment of lung lesions }\end{array}$} \\
\hline CARDILlo [119] & 2006 & 861 & 52.5 & 1.73 \\
\hline CARDILlo [120] & 2000 & 279 & 38 & 1.27 \\
\hline \multicolumn{5}{|l|}{ Mechanical abrasion } \\
\hline Gossot [121] & 2004 & 111 & 36.5 & 3.6 \\
\hline LANG-LAZDUNSKI [122] & 2003 & 167 & 93 & 3 \\
\hline \multicolumn{5}{|l|}{ Pleurectomy } \\
\hline Ayed [123] & 2003 & 100 & 48 & 2 \\
\hline
\end{tabular}

VATS: video-assisted thoracic surgery. ${ }^{\#}$ : median. 
intervention, only localised pleural symphysis at the site of minocycline instillation has been revealed, questioning the efficacy of any slurry-based procedure [152].

In a recent study of 294 thoracoscopic procedures performed in South Korea in patients with PSP, additional pleural abrasion did not decrease the recurrence of pneumothorax after wedge resection of bullae [153]. Pleurectomy is a valid procedure for spontaneous pneumothorax [120, 123, 154]. The main criticism is the complication rate and the difficulty in re-entering the chest; most surgeons perform an apical pleurectomy and abrasion lower down the chest to keep the chest cavity accessible in case another VATS procedure or thoracotomy would be required later in life.

In summary, talc poudrage with graded talc is safe and at present the most cost-effective approach to obtain a diffuse chemical pleurodesis preventing recurrence of PSP [155]. In clinical practice we use 2-4 g of talc (Steritalc F2; Novatech, La Ciotat, France) gently sprayed over the pleural surface by a hand-driven pump under visual control, avoiding contact between the tip of the catheter and the pleural surface. This allows a very diffuse distribution of talc particles (fig. 2) and avoids creating patchy areas of talc deposition. There are however some limitations: in the case of visible rupture of the visceral pleura the patient is referred to surgery for resection of the lung with air leakage.

\section{Lung procedures: VATS versus open thoracotomy}

VATS allows less invasive access $[156,157]$ to the thoracic cavity and represents the surgical treatment of choice. BARKER et al. [158] recently published a meta-analysis on the management of PSP by VATS or open thoracotomy. They identified 29 studies (four randomised and 25 non-randomised) and found a four-fold increase in recurrence rate of pneumothorax after VATS in comparison with open thoracotomy. Such a meta-analysis mixing randomised and non-randomised studies and compiling more than 20 years of VATS series is highly questionable [159]. A subsequent analysis did not confirm these findings when looking at randomised trials alone and showed a reduction in analgesia use and shorter hospital stays in patients treated by VATS compared with open thoracotomy [160]. In addition to demonstrating equivalent success rates for VATS compared with open thoracotomy [161-163], randomised controlled trials have demonstrated physiological benefits of VATS over thoracotomy including post-operative spirometry [161] and gas exchange [162]. There is a demonstrable "learning curve" in the use of VATS, which may explain the higher recurrence rates for this technique seen in the earlier reported series [164].

There are many surgical procedures that have been developed over the years (table 5). NAUNHEIM et al. [165] showed in a multivariate analysis that failure to excise the lung apex was the only significant predictive factor of recurrence of PSP. In this retrospective study, 101 (90\%) out of 113 patients surprisingly benefited from some pleurodesis, either mechanical or chemical. The decision about when to excise blebs or bullae remains a point of discussion. Electro- or cold coagulation remains controversial. Evidence shows that bullectomy is better in terms of recurrence compared with bullae ligation [120, 160]. SАКАмото et al. [166] showed in a retrospective study that coverage of stapling with absorbable mesh after bullectomy seems to improve the success rate of definitive management of PSP. An endobronchial approach using valves to control localised air leaks might offer a promising future treatment [167].

VATS requires double lumen tube intubation, general anaesthesia and an operating theatre but is much less invasive than thoracotomy and is currently the preferred surgical approach for the treatment of pneumothorax [157].

FIGURE 2 Talc poudrage technique. Talc is gently sprayed by a hand-driven pump under visual control. Avoid using talc from pressurised canisters.

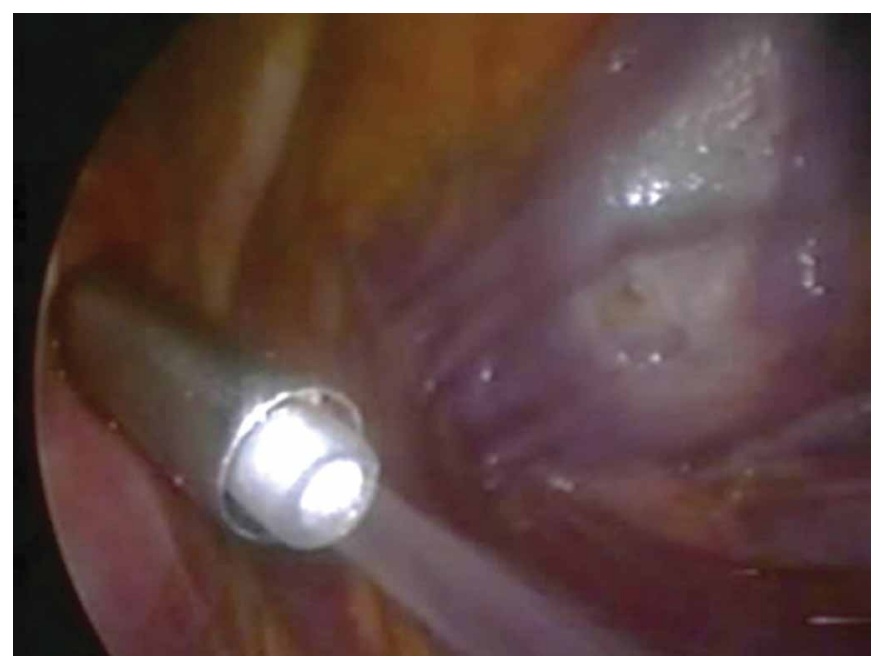


TABLE 5 Surgical procedures for persistent or recurrent primary spontaneous pneumothorax

\begin{tabular}{ll} 
Strategy & Comment \\
\hline $\begin{array}{l}\text { Routine excision of the apex of the lung } \\
\text { Selective excision of blebs or bullae }\end{array}$ & $\begin{array}{l}\text { Controversial } \\
\text { Controversial as not evidence-based for } \\
\text { pulmonologists; general agreement among } \\
\text { surgeons } \\
\text { Controversial but better results than bullae } \\
\text { Bullectomy }\end{array}$ \\
$\begin{array}{l}\text { ligation in non-randomised studies } \\
\text { Toverage of staple line with absorbable mesh }\end{array}$ & $\begin{array}{l}\text { Controversial } \\
\text { Electro- or cold coagulation of blebs and bullae }\end{array}$ \\
Endobronchial valves to close persistent air leak & $\begin{array}{l}\text { Still anecdotal } \\
\text { Talc poudrage }\end{array}$ \\
$\begin{array}{l}95 \% \text { success rate at follow-up; not advisable } \\
\text { as sole treatment in cases of significant bullae }\end{array}$
\end{tabular}

POMPEO et al. [168] performed a randomised study in 2007 comparing awake VATS (with thoracic epidural analgesia) with conventional general anaesthesia. They were able to demonstrate a significant reduction not only in peri-operative pain score and nursing care, but in length of hospital stay and total costs. Such a new approach is interesting, as many other groups have reported less invasive VATS strategies using small calibre instruments [113, 169] or uniportal access [170-172] to the thoracic cavity.

In summary, VATS is the preferred surgical approach over open thoracotomy. There is no conclusive evidence regarding the management of the lung parenchyma in the prevention of recurrence of PSP but some kind of pleurodesis, either mechanical or using talc poudrage, has to be applied to decrease the risk of recurrence of PSP. We also need more randomised controlled trials of these different strategies, especially well-designed prospective trials addressing the points discussed: the management of the lung parenchyma, the pleurodesis technique and the efficacy of VATS compared with medical thoracoscopy.

\section{Post-procedure pain control}

Pain is a common complication following pleurodesis procedures with talc or tetracyclines, despite the use of intrapleural xylocaine injection $[4,173,174]$. Seven centres were involved in a randomised multicentre study comparing talc poudrage with chest tube drainage [115]. Pain, as assessed by visual analogue scale (VAS), was significantly higher in the talc poudrage group. Interestingly, such a difference did not exist on the day of the intervention. When further analysing these results, it was found that three out of the seven centres did not use any opioids at all and did not have any systematic pain control policy. Excluding the patients receiving no opioids, there was no significant difference in reported pain levels.

In summary, it may be that pain after pleurodesis, whatever the technique, is often neglected by clinicians, especially in the days after the intervention. It is important for every institution to have not only a systematic assessment of pain by using VAS, but also a systematic pain control policy. After VATS for PSP, better use of analgesia implemented by nurses could perhaps decrease the incidence of chronic pain, which has been reported in $32-46 \%$ of patients $[175,176]$. In a non-randomised study of analgesia following VATS, percutaneous thoracic paravertebral catheter and morphine patient-controlled analgesia was the technique associated with lowest levels of post-operative pain, although this difference was not statistically significant [177].

\section{Conclusions and further questions}

The exact incidence of PSP is not known. The literature would support initial intervention with simple aspiration in symptomatic individuals at first presentation. As recently shown [7, 104], Heimlich valves may offer a promising and alternative method of ambulatory management in PSP if confirmed in large-scale randomised controlled trials [16]. Definitive treatment with thoracoscopic poudrage/ pleurectomy is often administered in high-risk groups; however, it is not necessary for most patients at their first presentation, as the majority will not recur during their lifetime. Smoking cessation remains the only reversible risk factor known to reduce the chance of recurrence, although we should not neglect the deleterious role of marijuana smoking as a risk of PSP. Aggressive smoking cessation advice is therefore given to all patients who smoke at the first episode of pneumothorax.

There are several questions that require further research. 1) What is the true incidence of PSP? 2) Are there subgroups with a high risk of recurrence of PSP that warrant definitive treatment after their first presentation? 3) Should all PSP be treated with conservative or ambulatory care? 4) Is there a role for genetic testing and thoracic high-resolution CT scanning in all cases of PSP? 5) What are the relative 
benefits of talc poudrage versus talc poudrage and bullectomy in recurrence prevention? 6) What is the role of lung parenchyma resection in recurrence prevention of PSP?

\section{Acknowledgements}

We wish to thank Gervaise Badet (librarian of the University of Geneva Faculty of Medicine (Geneva, Switzerland)) for her support in setting up the literature database shared by all the Task Force members.

\section{References}

1 Laënnec RTH. De l'auscultation mediate, ou traité du diagnostic des maladies des poumons et du coeur, fondé principalement sur ce nouveau moyen d'exploration [On mediate auscultation, or treatise on the diseases of the lungs and heart, based principally on this new method of investigation]. Paris, Brosson and Chaudé, 1819. Baumann MH. Management of spontaneous pneumothorax. Clin Chest Med 2006; 27: 369-381.

3 Sadikot RT, Greene T, Meadows K, et al. Recurrence of primary spontaneous pneumothorax. Thorax 1997; 52: 805-809.

4 Chen JS, Chan WK, Tsai KT, et al. Simple aspiration and drainage and intrapleural minocycline pleurodesis versus simple aspiration and drainage for the initial treatment of primary spontaneous pneumothorax: an open-label, parallel-group, prospective, randomised, controlled trial. Lancet 2013; 381: 1277-1282. O'Rourke JP, Yee ES. Civilian spontaneous pneumothorax. Treatment options and long-term results. Chest 1989; 96: 1302-1306.

6 MacDuff A, Arnold A, Harvey J. Management of spontaneous pneumothorax: British Thoracic Society pleural disease guideline 2010. Thorax 2010; 65: Suppl. 2, ii18-ii31.

7 Massongo M, Leroy S, Scherpereel A, et al. Outpatient management of primary spontaneous pneumothorax: a prospective study. Eur Respir J 2014; 43: 582-590.

8 Noppen M. Spontaneous pneumothorax: epidemiology, pathophysiology and cause. Eur Respir Rev 2010; 19: 217-219.

9 Baumann MH, Strange C. Treatment of spontaneous pneumothorax: a more aggressive approach? Chest 1997; 112: 789-804.

10 Kelly AM, Clooney M. Deviation from published guidelines in the management of primary spontaneous pneumothorax in Australia. Intern Med J 2008; 38: 64-67.

11 Smit HJ, Chatrou M, Postmus PE. The impact of spontaneous pneumothorax, and its treatment, on the smoking behaviour of young adult smokers. Respir Med 1998; 92: 1132-1136.

12 Janssen J, Cardillo G. Primary spontaneous pneumothorax: towards outpatient treatment and abandoning chest tube drainage. Respiration 2011; 82: 201-203.

13 Lee P. Primary spontaneous pneumothorax: to pleurodese or not? Lancet 2013; 381: 1252-1254.

14 Hassani B, Foote J, Borgundvaag B. Outpatient management of primary spontaneous pneumothorax in the emergency department of a community hospital using a small-bore catheter and a Heimlich valve. Acad Emerg Med 2009; 16: 513-518.

15 Zehtabchi S, Rios CL. Management of emergency department patients with primary spontaneous pneumothorax: needle aspiration or tube thoracostomy? Ann Emerg Med 2008; 51: 91-100.

16 Brims FJ, Maskell NA. Ambulatory treatment in the management of pneumothorax: a systematic review of the literature. Thorax 2013; 68: 664-669.

17 Bridevaux PO, Tschopp JM, Cardillo G, et al. Short-term safety of thoracoscopic talc pleurodesis for recurrent primary spontaneous pneumothorax: a prospective European multicentre study. Eur Respir J 2011; 38: 770-773.

18 Noppen M, Alexander P, Driesen P, et al. Quantification of the size of primary spontaneous pneumothorax: accuracy of the Light index. Respiration 2001; 68: 396-399.

19 Bense L, Eklund G, Wiman LG. Smoking and the increased risk of contracting spontaneous pneumothorax. Chest 1987; 92: 1009-1012.

20 Gupta D, Hansell A, Nichols T, et al. Epidemiology of pneumothorax in England. Thorax 2000; 55: 666-671.

21 Baumann MH, Strange C, Heffner JE, et al. Management of spontaneous pneumothorax: an American College of Chest Physicians Delphi consensus statement. Chest 2001; 119: 590-602.

22 Johnson MK, Smith RP, Morrison D, et al. Large lung bullae in marijuana smokers. Thorax 2000; 55: 340-342.

23 Wu TC, Tashkin DP, Djahed B, et al. Pulmonary hazards of smoking marijuana as compared with tobacco. N Engl J Med 1988; 318: 347-351.

24 Feldman AL, Sullivan JT, Passero MA, et al. Pneumothorax in polysubstance-abusing marijuana and tobacco smokers: three cases. J Subst Abuse 1993; 5: 183-186.

25 Beshay M, Kaiser H, Niedhart D, et al. Emphysema and secondary pneumothorax in young adults smoking cannabis. Eur J Cardiothorac Surg 2007; 32: 834-838.

26 Alifano M, Forti Parri SN, Bonfanti B, et al. Atmospheric pressure influences the risk of pneumothorax: beware of the storm! Chest 2007; 131: 1877-1882.

27 Bertolaccini L, Alemanno L, Rocco G, et al. Air pollution, weather variations and primary spontaneous pneumothorax. J Thorac Dis 2010; 2: 9-15.

28 Withers JN, Fishback ME, Kiehl PV, et al. Spontaneous pneumothorax. Suggested etiology and comparison of treatment methods. Am J Surg 1964; 108: 772-776.

29 Marquette $\mathrm{CH}$, Marx A, Leroy S, et al. Simplified stepwise management of primary spontaneous pneumothorax: a pilot study. Eur Respir J 2006; 27: 470-476.

30 Rousset-Jablonski C, Alifano M, Plu-Bureau G, et al. Catamenial pneumothorax and endometriosis-related pneumothorax: clinical features and risk factors. Hum Reprod 2011; 26: 2322-2329.

31 Visouli AN, Zarogoulidis K, Kougioumtzi I, et al. Catamenial pneumothorax. J Thorac Dis 2014; 6: Suppl. 4, S448-S460.

Alifano M, Roth T, Broët SC, et al. Catamenial pneumothorax: a prospective study. Chest 2003; 124: 1004-1008.

Alifano M, Jablonski C, Kadiri $\mathrm{H}$, et al. Catamenial and noncatamenial, endometriosis-related or nonendometriosis-related pneumothorax referred for surgery. Am J Respir Crit Care Med 2007; 176: 1048-1053. 
Bense L, Wiman LG, Hedenstierna G. Onset of symptoms in spontaneous pneumothorax: correlations to physical activity. Eur J Respir Dis 1987; 71: 181-186.

Gill A. Cannabis, pneumothorax and lung bullae. J R Soc Med 2006; 99: 169-170.

Miller AC. Spontaneous pneumothorax. In: Light RW, Lee YCG, eds. Textbook of Pleural Diseases. 2nd Edn. London, Hodder Arnold, 2008; pp. 515-532.

Leigh-Smith S, Harris T. Tension pneumothorax - time for a re-think? Emerg Med J 2005; 22: 8-16.

Brown SG, Ball EL, Macdonald SP, et al. Spontaneous pneumothorax; a multicentre retrospective analysis of emergency treatment, complications and outcomes. Intern Med J 2014; 44: 450-457.

Glazer HS, Anderson DJ, Wilson BS, et al. Pneumothorax: appearance on lateral chest radiographs. Radiology 1989; 173: 707-711.

Greene R, McLoud TC, Stark P. Pneumothorax. Semin Roentgenol 1977; 12: 313-325.

Bradley M, Williams C, Walshaw MJ. The value of routine expiratory chest films in the diagnosis of pneumothorax. Arch Emerg Med 1991; 8: 115-116.

Bungay HK, Berger J, Traill ZC, et al. Pneumothorax post CT-guided lung biopsy: a comparison between detection on chest radiographs and CT. Br J Radiol 1999; 72: 1160-1163.

Tocino IM, Miller MH, Frederick PR, et al. CT detection of occult pneumothorax in head trauma. AJR Am J Roentgenol 1984; 143: 987-990.

Rowan KR, Kirkpatrick AW, Liu D, et al. Traumatic pneumothorax detection with thoracic US: correlation with chest radiography and CT - initial experience. Radiology 2002; 225: 210-214.

Voggenreiter G, Aufmkolk M, Majetschak M, et al. Efficiency of chest computed tomography in critically ill patients with multiple traumas. Crit Care Med 2000; 28: 1033-1039.

Davies HE, Wathen CG, Gleeson FV. The risks of radiation exposure related to diagnostic imaging and how to minimise them. BMJ 2011; 342: d947.

Kelly AM, Weldon D, Tsang AY, et al. Comparison between two methods for estimating pneumothorax size from chest X-rays. Respir Med 2006; 100: 1356-1359.

Lichtenstein DA, Mezière G, Lascols N, et al. Ultrasound diagnosis of occult pneumothorax. Crit Care Med 2005; 33: 1231-1238.

Kirkpatrick AW, Sirois M, Laupland KB, et al. Hand-held thoracic sonography for detecting post-traumatic pneumothoraces: the Extended Focused Assessment with Sonography for Trauma (EFAST). J Trauma 2004; 57: 288-295.

Knudtson JL, Dort JM, Helmer SD, et al. Surgeon-performed ultrasound for pneumothorax in the trauma suite. J Trauma 2004; 56: 527-530.

Blaivas M, Lyon M, Duggal S. A prospective comparison of supine chest radiography and bedside ultrasound for the diagnosis of traumatic pneumothorax. Acad Emerg Med 2005; 12: 844-849.

Soldati G, Testa A, Sher S, et al. Occult traumatic pneumothorax: diagnostic accuracy of lung ultrasonography in the emergency department. Chest 2008; 133: 204-211.

Jaffer U, McAuley D. Best evidence topic report. Transthoracic ultrasonography to diagnose pneumothorax in trauma. Emerg Med J 2005; 22: 504-505.

Goodman TR, Traill ZC, Phillips AJ, et al. Ultrasound detection of pneumothorax. Clin Radiol 1999; 54: 736-739.

Brook OR, Beck-Razi N, Abadi S, et al. Sonographic detection of pneumothorax by radiology residents as part of extended focused assessment with sonography for trauma. J Ultrasound Med 2009; 28: 749-755.

Galbois A, Ait-Oufella H, Baudel JL, et al. Pleural ultrasound compared with chest radiographic detection of pneumothorax resolution after drainage. Chest 2010; 138: 648-655.

Dulchavsky SA, Schwarz KL, Kirkpatrick AW, et al. Prospective evaluation of thoracic ultrasound in the detection of pneumothorax. J Trauma 2001; 50: 201-205.

Chen $\mathrm{CH}$, Liao WC, Liu YH, et al. Secondary spontaneous pneumothorax: which associated conditions benefit from pigtail catheter treatment? Am J Emerg Med 2012; 30: 45-50.

Guo Y, Xie C, Rodriguez RM, et al. Factors related to recurrence of spontaneous pneumothorax. Respirology 2005; 10: 378-384.

Flume PA, Strange C, Ye X, et al. Pneumothorax in cystic fibrosis. Chest 2005; 128: 720-728.

Flume PA. Pneumothorax in cystic fibrosis. Curr Opin Pulm Med 2011; 17: 220-225.

Hafen GM, Ukoumunne OC, Robinson PJ. Pneumothorax in cystic fibrosis: a retrospective case series. Arch Dis Child 2006; 91: 924-925.

Mert A, Bilir M, Akman C, et al. Spontaneous pneumothorax: a rare complication of miliary tuberculosis. Ann Thorac Cardiovasc Surg 2001; 7: 45-48.

Zhang $\mathrm{W}, \mathrm{Hu} \mathrm{Y}$, Chen L, et al. Pleural aspergillosis complicated by recurrent pneumothorax: a case report. J Med Case Rep 2010; 4: 180.

Winne L, Praet M, Brusselle G, et al. Bilateral spontaneous pneumothorax in a patient with pulmonary rheumatoid nodules, secondary infected by Aspergillus. Clin Rheumatol 2007; 26: 1180-1182.

Murry CE, Schmidt RA. Tissue invasion by Pneumocystis carinii: a possible cause of cavitary pneumonia and pneumothorax. Hum Pathol 1992; 23: 1380-1387.

Donahue DM, Wright CD, Viale G, et al. Resection of pulmonary blebs and pleurodesis for spontaneous pneumothorax. Chest 1993; 104: 1767-1769.

Lesur O, Delorme N, Fromaget JM, et al. Computed tomography in the etiologic assessment of idiopathic spontaneous pneumothorax. Chest 1990; 98: 341-347.

Noppen M, De Keukeleire T. Pneumothorax. Respiration 2008; 76: 121-127.

Light RW. Pneumothorax. In: Light RW. Pleural Diseases. 5th Edn. Philadelphia, Lippincott Williams and Wilkins, 2007; pp. 306-339.

Kelly AM, Druda D. Comparison of size classification of primary spontaneous pneumothorax by three international guidelines: a case for international consensus? Respir Med 2008; 102: 1830-1832.

Hoi K, Turchin B, Kelly AM. How accurate is the Light index for estimating pneumothorax size?. Australas Radiol 2007; 51: 196-198.

Baronofsky ID, Warden HG, Kaufman JL, et al. Bilateral therapy for unilateral spontaneous pneumothorax. J Thorac Surg 1957; 34: 310-319. 
Mitlehner W, Friedrich M, Dissmann W. Value of computer tomography in the detection of bullae and blebs in patients with primary spontaneous pneumothorax. Respiration 1992; 59: 221-227.

Sihoe AD, Yim AP, Lee TW, et al. Can CT scanning be used to select patients with unilateral primary spontaneous pneumothorax for bilateral surgery? Chest 2000; 118: 380-383.

Schramel FM, Sutedja TG, Janssen JP, et al. Prognostic factors in patients with spontaneous pneumothorax treated with video-assisted thoracoscopy. Diagn Ther Endosc 1995; 2: 1-5.

Belchis DA, Shekitka K, Gocke CD. A unique, histopathologic lesion in a subset of patients with spontaneous pneumothorax. Arch Pathol Lab Med 2012; 136: 1522-1527.

Vanderschueren RG. Le talcage pleural dans le pneumothorax spontane [Pleural talcage in patients with spontaneous pneumothorax]. Poumon Coeur 1981; 37: 273-276.

Radomsky J, Becker HP, Hartel W. Pleuraporositat beim idiopathischen Spontanpneumothorax [Pleural porosity in idiopathic spontaneous pneumothorax]. Pneumologie 1989; 43: 250-253.

Weissberg D, Refaely Y. Pneumothorax: experience with 1,199 patients. Chest 2000; 117: 1279-1285.

Hatz RA, Kaps MF, Meimarakis G, et al. Long-term results after video-assisted thoracoscopic surgery for first-time and recurrent spontaneous pneumothorax. Ann Thorac Surg 2000; 70: 253-257.

Janssen JP, Schramel FM, Sutedja TG, et al. Videothoracoscopic appearance of first and recurrent pneumothorax. Chest 1995; 108: 330-334.

Smit HJ, Golding RP, Schramel FM, et al. Lung density measurements in spontaneous pneumothorax demonstrate airtrapping. Chest 2004; 125: 2083-2090.

Casali C, Stefani A, Ligabue G, et al. Role of blebs and bullae detected by high-resolution computed tomography and recurrent spontaneous pneumothorax. Ann Thorac Surg 2013; 95: 249-255.

Ohata M, Suzuki H. Pathogenesis of spontaneous pneumothorax. With special reference to the ultrastructure of emphysematous bullae. Chest 1980; 77: 771-776.

Masshoff W, Höfer W. Zur Pathologie des sogenannten idiopathischen Spontanpneumothorax [Pathology of so-called idiopathic spontaneous pneumothorax]. Dtsch Med Wochenschr 1973; 98: 801-805.

Noppen M, Dekeukeleire T, Hanon S, et al. Fluorescein-enhanced autofluorescence thoracoscopy in patients with primary spontaneous pneumothorax and normal subjects. Am J Respir Crit Care Med 2006; 174: 26-30.

Nakanishi K. Long-term effect of a thoracoscopic stapled bullectomy alone for preventing the recurrence of primary spontaneous pneumothorax. Surg Today 2009; 39: 553-557.

Horio $\mathrm{H}$, Nomori $\mathrm{H}$, Kobayashi $\mathrm{R}$, et al. Impact of additional pleurodesis in video-assisted thoracoscopic bullectomy for primary spontaneous pneumothorax. Surg Endosc 2002; 16: 630-634.

Loubani M, Lynch V. Video assisted thoracoscopic bullectomy and acromycin pleurodesis: an effective treatment for spontaneous pneumothorax. Respir Med 2000; 94: 888-890.

Haynes D, Baumann MH. Pleural controversy: aetiology of pneumothorax. Respirology 2011; 16: 604-610.

Henry M, Arnold T, Harvey J. BTS guidelines for the management of spontaneous pneumothorax. Thorax 2003; 58: Suppl. 2, ii39-ii52.

Harvey J, Prescott RJ. Simple aspiration versus intercostal tube drainage for spontaneous pneumothorax in patients with normal lungs. British Thoracic Society Research Committee. BMJ 1994; 309: 1338-1339.

Andrivet P, Djedaini K, Teboul JL, et al. Spontaneous pneumothorax. Comparison of thoracic drainage vs immediate or delayed needle aspiration. Chest 1995; 108: 335-339.

Noppen M, Alexander P, Driesen P, et al. Manual aspiration versus chest tube drainage in first episodes of primary spontaneous pneumothorax: a multicenter, prospective, randomized pilot study. Am J Respir Crit Care Med 2002; 165: 1240-1244.

Ayed AK, Chandrasekaran C, Sukumar M. Aspiration versus tube drainage in primary spontaneous pneumothorax: a randomised study. Eur Respir J 2006; 27: 477-482.

Parlak M, Uil SM, van den Berg JW. A prospective, randomised trial of pneumothorax therapy: manual aspiration versus conventional chest tube drainage. Respir Med 2012; 106: 1600-1605.

Ho KK, Ong ME, Koh MS, et al. A randomized controlled trial comparing minichest tube and needle aspiration in outpatient management of primary spontaneous pneumothorax. Am J Emerg Med 2011; 29: 1152-1157.

Kaneda H, Nakano T, Taniguchi Y, et al. Three-step management of pneumothorax: time for a re-think on initial management. Interact Cardiovasc Thorac Surg 2013; 16: 186-192.

Soulsby T. British Thoracic Society guidelines for the management of spontaneous pneumothorax: do we comply with them and do they work? J Accid Emerg Med 1998; 15: 317-321.

Iepsen UW, Ringbaek T. Small-bore chest tubes seem to perform better than larger tubes in treatment of spontaneous pneumothorax. Dan Med J 2013; 60: A4644.

Kuo HC, Lin YJ, Huang CF, et al. Small-bore pigtail catheters for the treatment of primary spontaneous pneumothorax in young adolescents. Emerg Med J 2013; 30: e17.

Voisin F, Sohier L, Rochas Y, et al. Ambulatory management of large spontaneous pneumothorax with pigtail catheters. Ann Emerg Med 2014; 64: 222-228.

Lai SM, Tee AK. Outpatient treatment of primary spontaneous pneumothorax using a small-bore chest drain with a Heimlich valve: the experience of a Singapore emergency department. Eur J Emerg Med 2012; 19: 400-404.

Waller DA, McConnell SA, Rajesh PB. Delayed referral reduces the success of video-assisted thoracoscopic surgery for spontaneous pneumothorax. Respir Med 1998; 92: 246-249.

Jablonski S, Brocki M, Wawrzycki M, et al. Efficacy assessment of the drainage with permanent airflow measurement in the treatment of pneumothorax with air leak. Thorac Cardiovasc Surg 2014; 62: 509-515. 1997; 10: 1372-1379.

Tschopp JM, Rami-Porta R, Noppen M, et al. Management of spontaneous pneumothorax: state of the art. Eur Respir J 2006; 28: 637-650. travel: British Thoracic Society recommendations. Thorax 2011; 66: Suppl. 1, i1-i30.

Hu X, Cowl CT, Baqir M, et al. Air travel and pneumothorax. Chest 2014; 145: 688-694.

Duchateau FX, Legrand JM, Verner L, et al. Commercial aircraft repatriation of patients with pneumothorax. Air Med J 2013; 32: 200-202. 
Chou SH, Li HP, Lee JY, et al. Needlescopic video-assisted thoracic surgery for primary spontaneous pneumothorax. Minim Invasive Ther Allied Technol 2009; 18: 221-224.

Schoenenberger RA, Haefeli WE, Weiss P, et al. Timing of invasive procedures in therapy for primary and secondary spontaneous pneumothorax. Arch Surg 1991; 126: 764-766.

Tschopp JM, Boutin C, Astoul P, et al. Talcage by medical thoracoscopy for primary spontaneous pneumothorax is more cost-effective than drainage: a randomised study. Eur Respir J 2002; 20: 1003-1009.

Boutin C, Viallat JR, Aelony Y. Practical Thoracoscopy. Heidelberg, Springer, 1991.

el Khawand C, Marchandise FX, Mayne A, et al. Pneumothorax spontane. Resultats du talcage pleural sous thoracoscopie [Spontaneous pneumothorax. Results of pleural talc therapy using thoracoscopy]. Rev Mal Respir $1995 ; 12: 275-281$.

Györik S, Erni S, Studler U, et al. Long-term follow-up of thoracoscopic talc pleurodesis for primary spontaneous pneumothorax. Eur Respir J 2007; 29: 757-760.

Cardillo G, Carleo F, Giunti R, et al. Videothoracoscopic talc poudrage in primary spontaneous pneumothorax: a single-institution experience in 861 cases. J Thorac Cardiovasc Surg 2006; 131: 322-328.

Cardillo G, Facciolo F, Giunti R, et al. Videothoracoscopic treatment of primary spontaneous pneumothorax: a 6-year experience. Ann Thorac Surg 2000; 69: 357-361.

Gossot D, Galetta D, Stern JB, et al. Results of thoracoscopic pleural abrasion for primary spontaneous pneumothorax. Surg Endosc 2004; 18: 466-471.

Lang-Lazdunski L, Chapuis O, Bonnet PM, et al. Videothoracoscopic bleb excision and pleural abrasion for the treatment of primary spontaneous pneumothorax: long-term results. Ann Thorac Surg 2003; 75: 960-965.

Ayed AK. Suction versus water seal after thoracoscopy for primary spontaneous pneumothorax: prospective randomized study. Ann Thorac Surg 2003; 75: 1593-1596.

Brandt HJ, Loddenkemper R, Mai J. Atlas der diagnostischen Thorakoscopie. Indikationen - Technik [Atlas of diagnostic thoracoscopy. Indications - Technique]. Stuttgart, Thieme, 1983.

Cardillo G, Carleo F, Carbone L, et al. Long-term lung function following videothoracoscopic talc poudrage for primary spontaneous recurrent pneumothorax. Eur J Cardiothorac Surg 2007; 31: 802-805.

Gaensler EA. Parietal pleurectomy for recurrent spontaneous pneumothorax. Surg Gynecol Obstet 1956; 102: 293-308.

Rehse DH, Aye RW, Florence MG. Respiratory failure following talc pleurodesis. Am J Surg 1999; 177: 437-440. Campos JR, Werebe EC, Vargas FS, et al. Respiratory failure due to insufflated talc. Lancet 1997; 349: $251-252$. Light RW. Talc should not be used for pleurodesis. Am J Respir Crit Care Med 2000; 162: 2024-2026. Sahn SA. Talc should be used for pleurodesis. Am J Respir Crit Care Med 2000; 162: 2023-2024.

Werebe EC, Pazetti R, Milanez de Campos JR, et al. Systemic distribution of talc after intrapleural administration in rats. Chest 1999; 115: 190-193.

Fraticelli A, Robaglia-Schlupp A, Riera H, et al. Distribution of calibrated talc after intrapleural administration: an experimental study in rats. Chest 2002; 122: 1737-1741.

Navarro Jiménez C, Gómez Izquierdo L, Sánchez Gutiérrez C, et al. Análisis morfométrico y mineralógico de 14 muestras de talco usado para pleurodesis en distintos países de Europa y América [Morphometric and mineralogical analysis of 14 samples of talc used for pleurodesis in several European and American countries]. Neumosur 2005; 17: 197-202.

Maskell NA, Lee YC, Gleeson FV, et al. Randomized trials describing lung inflammation after pleurodesis with talc of varying particle size. Am J Respir Crit Care Med 2004; 170: 377-382.

Gonzalez AV, Bezwada V, Beamis JF Jr, et al. Lung injury following thoracoscopic talc insufflation: experience of a single North American center. Chest 2010; 137: 1375-1381.

Janssen JP, Collier G, Astoul P, et al. Safety of pleurodesis with talc poudrage in malignant pleural effusion: a prospective cohort study. Lancet 2007; 369: 1535-1539.

Lange P, Mortensen J, Groth S. Lung function 22-35 years after treatment of idiopathic spontaneous pneumothorax with talc poudrage or simple drainage. Thorax 1988; 43: 559-561.

Doddoli C, Barlési F, Fraticelli A, et al. Video-assisted thoracoscopic management of recurrent primary spontaneous pneumothorax after prior talc pleurodesis: a feasible, safe and efficient treatment option. Eur $J$ Cardiothorac Surg 2004; 26: 889-892.

Cardillo G, Facciolo F, Regal M, et al. Recurrences following videothoracoscopic treatment of primary spontaneous pneumothorax: the role of redo-videothoracoscopy. Eur J Cardiothorac Surg 2001; 19: 396-399.

Schramel FM, Sutedja TG, Braber JC, et al. Cost-effectiveness of video-assisted thoracoscopic surgery versus conservative treatment for first time or recurrent spontaneous pneumothorax. Eur Respir J 1996; 9: $1821-1825$. Noppen M. Who's (still) afraid of talc? Eur Respir J 2007; 29: 619-621.

Hunt I, Barber B, Southon R, et al. Is talc pleurodesis safe for young patients following primary spontaneous pneumothorax? Interact Cardiovasc Thorac Surg 2007; 6: 117-120.

Ramos-Izquierdo R, Moya J, Macia I, et al. Treatment of primary spontaneous pneumothorax by videothoracoscopic talc pleurodesis under local anesthesia: a review of 133 procedures. Surg Endosc 2010; 24: 984-987.

44 Sepehripour AH, Nasir A, Shah R. Does mechanical pleurodesis result in better outcomes than chemical pleurodesis for recurrent primary spontaneous pneumothorax? Interact Cardiovasc Thorac Surg 2012; 14: 307-311.

Moreno-Merino S, Congregado M, Gallardo G, et al. Comparative study of talc poudrage versus pleural abrasion for the treatment of primary spontaneous pneumothorax. Interact Cardiovasc Thorac Surg 2012; 15: 81-85.

How CH, Hsu HH, Chen JS. Chemical pleurodesis for spontaneous pneumothorax. J Formos Med Assoc 2013; 112: 749-755.

Bresticker MA, Oba J, LoCicero J 3rd, et al. Optimal pleurodesis: a comparison study. Ann Thorac Surg 1993; 55: 364-366.

Heffner JE, Unruh LC. Tetracycline pleurodesis. Adios, farewell, adieu. Chest 1992; 101: 5-7. Aelony Y. Talc pleurodesis. Talc slurry vs talc poudrage. Chest 1995; 108: 289.

Berger R. Pleurodesis for spontaneous pneumothorax. Will the procedure of choice please stand up? Chest 1994; 106: 992-994. 
151 Wong RH, Ng CS, Underwood MJ. Iodine pleurodesis - a word of caution. Eur J Cardiothorac Surg 2012; 41: 1209.

152 Chen JS, Tsai KT, Hsu HH, et al. Intrapleural minocycline following simple aspiration for initial treatment of primary spontaneous pneumothorax. Respir Med 2008; 102: 1004-1010.

153 Park JS, Han WS, Kim HK, et al. Pleural abrasion for mechanical pleurodesis in surgery for primary spontaneous pneumothorax: is it effective? Surg Laparosc Endosc Percutan Tech 2012; 22: 62-64.

154 Qureshi R, Nugent A, Hayat J, et al. Should surgical pleurectomy for spontaneous pneumothorax be always thoracoscopic? Interact Cardiovasc Thorac Surg 2008; 7: 569-572.

155 Aelony Y. Talc pleurodesis and acute respiratory distress syndrome. Lancet 2007; 369: 1494-1496.

156 LoCicero J 3rd. Video-assisted thoracoscopy’s anniversary. Chest 1997; 111: 268-269.

157 Treasure T. Minimally invasive surgery for pneumothorax: the evidence, changing practice and current opinion. J R Soc Med 2007; 100: 419-422.

158 Barker A, Maratos EC, Edmonds L, et al. Recurrence rates of video-assisted thoracoscopic versus open surgery in the prevention of recurrent pneumothoraces: a systematic review of randomised and non-randomised trials. Lancet 2007; 370: 329-335.

159 Treasure T. Minimal access surgery for pneumothorax. Lancet 2007; 370: 294-295.

160 Vohra HA, Adamson L, Weeden DF. Does video-assisted thoracoscopic pleurectomy result in better outcomes than open pleurectomy for primary spontaneous pneumothorax? Interact Cardiovasc Thorac Surg 2008; 7: 673-677.

161 Waller DA, Forty J, Morritt GN. Video-assisted thoracoscopic surgery versus thoracotomy for spontaneous pneumothorax. Ann Thorac Surg 1994; 58: 372-376.

162 Sekine Y, Miyata Y, Yamada K, et al. Video-assisted thoracoscopic surgery does not deteriorate postoperative pulmonary gas exchange in spontaneous pneumothorax patients. Eur J Cardiothorac Surg 1999; 16: 48-53.

163 Freixinet JL, Canalís E, Juliá G, et al. Axillary thoracotomy versus videothoracoscopy for the treatment of primary spontaneous pneumothorax. Ann Thorac Surg 2004; 78: 417-420.

164 Waller DA. Video-assisted thoracoscopic surgery for spontaneous pneumothorax - a 7-year learning experience. Ann R Coll Surg Engl 1999; 81: 387-392.

165 Naunheim KS, Mack MJ, Hazelrigg SR, et al. Safety and efficacy of video-assisted thoracic surgical techniques for the treatment of spontaneous pneumothorax. J Thorac Cardiovasc Surg 1995; 109: 1198-1203.

166 Sakamoto K, Takei H, Nishii T, et al. Staple line coverage with absorbable mesh after thoracoscopic bullectomy for spontaneous pneumothorax. Surg Endosc 2004; 18: 478-481

167 Mahajan AK, Doeing DC, Hogarth DK. Isolation of persistent air leaks and placement of intrabronchial valves. J Thorac Cardiovasc Surg 2013; 145: 626-630.

168 Pompeo E, Tacconi F, Mineo D, et al. The role of awake video-assisted thoracoscopic surgery in spontaneous pneumothorax. J Thorac Cardiovasc Surg 2007; 133: 786-790.

169 Kim JT, Kim KH, Yoon YH, et al. A 2-mm videothoracoscopic incision for primary spontaneous pneumothorax. Asian Cardiovasc Thorac Ann 2001; 9: 27-30.

170 Malik M, Black EA. Fast-track video-assisted bullectomy and pleurectomy for pneumothorax: initial experience and description of technique. Eur J Cardiothorac Surg 2009; 36: 906-909.

171 Berlanga LA, Gigirey O. Uniportal video-assisted thoracic surgery for primary spontaneous pneumothorax using a single-incision laparoscopic surgery port: a feasible and safe procedure. Surg Endosc 2011; 25: 2044-2047.

172 Rocco G, Martin-Ucar A, Passera E. Uniportal VATS wedge pulmonary resections. Ann Thorac Surg 2004; 77: 726-728.

173 Chen JS, Hsu HH, Kuo SW, et al. Effects of additional minocycline pleurodesis after thoracoscopic procedures for primary spontaneous pneumothorax. Chest 2004; 125: 50-55.

174 Chen JS, Hsu HH, Chen RJ, et al. Additional minocycline pleurodesis after thoracoscopic surgery for primary spontaneous pneumothorax. Am J Respir Crit Care Med 2006; 173: 548-554.

175 Passlick B, Born C, Sienel W, et al. Incidence of chronic pain after minimal-invasive surgery for spontaneous pneumothorax. Eur J Cardiothorac Surg 2001; 19: 355-358.

176 Sostheim U, Steger V, Friedel G, et al. Long-term sequelae and risk behaviour in patients operated for spontaneous pneumothorax. Interact Cardiovasc Thorac Surg 2012; 15: Suppl. 1, 034.

177 Khoshbin E, Al-Jilaihawi AN, Scott NB, et al. An audit of pain control pathways following video-assisted thoracoscopic surgery. Innovations 2011; 6: 248-252. 